\title{
IDDM susceptibility associated with polymorphisms in the insulin gene region A study of blacks, Caucasians and orientals
}

\author{
D.E. Undlien ${ }^{1}$, K.Hamaguchi $^{2}$, A.Kimura ${ }^{3}$, E.Tuomilehto-Wolf ${ }^{4}$, A.B.M.Swai ${ }^{5}$, D. G.McLarty ${ }^{5}$, J.Tuomilehto ${ }^{4}$, \\ E.Thorsby ${ }^{1}$, K.S. Ronningen ${ }^{1}$ \\ ${ }^{1}$ Institute of Transplantation Immunology, The National Hospital, Oslo, Norway \\ ${ }^{2}$ Internal Medicine I, Oita Medical University, Oita, Japan \\ ${ }^{3}$ Department of Genetics, Kyushu University, Japan \\ ${ }^{4}$ National Public Health Institute, Department of Epidemiolgy, Helsinki, Finland \\ ${ }^{5}$ Muhimbili Medical Centre, Dar-es-Salaam, Tanzania
}

Summary Previous studies have suggested an association between polymorphisms in the insulin gene region and insulin-dependent diabetes mellitus (IDDM). Most of the studies so far have been performed in Caucasoid populations. We have investigated 418 random IDDM patients and 422 healthy control subjects from three different ethnic groups; Tanzanian blacks, Norwegian Caucasians and Japanese orientals. Our data suggest that polymorphisms in the insulin gene region confer susceptibility to IDDM in Caucasians, and that a similar tendency though not statistically significant is observed among Tanzanian blacks, while no significant contribution is seen among Japanese orientals. We further demon- strate that the disease-associated genotype INS $+1+$ confers susceptibility independently of HLA class II alleles associated with IDDM. Compared to the contribution of particular HLA-DQ alleles in IDDM susceptibility, the additional risk conferred by the insulin gene region polymorphism is, however, small. Genotyping of the insulin gene region will therefore most probably not be a useful tool in the prediction of IDDM. [Diabetologia (1994) 37: Wingdingsx-Wingdingsx] [Diabetologia (1994) 37: 745-749]

Key words Insulin gene polymorphism, HLA class II genotypes, transracial comparison, IDDM, genetic susceptibility.
The HLA complex on chromosome 6, and in particular the HLA-DQ region, plays an important role in the genetic predisposition to IDDM [1]. Family studies have, however, shown that the concordance rate between monozygotic twins $(23-35 \%)$ exceeds that of HLA-identical siblings (6-19\%), indicating that other genes also contribute to the genetic susceptibility [2-4]. Genes at ten different loci have been found to be asso-

Received: 30 November 1993

and in revised form: 7 February 1994

Corresponding author: Dr. D. E. Undlien, Institute of Transplantation Immunology, The National Hospital, N-0027 Oslo, Norway

Abbreviations: NOD mice, Non-obese diabetic mice; IGF2, insulin-like growth factor 2; VNTR, variable number of tandem repeats; PCR-SSO, polymerase chain reaction - sequence specific oligonucleotide; RR, relative risk; $\mathrm{Kb}$, kilobasepair; $\mathrm{CI}$, confidence interval; $\mathrm{OR}_{\mathrm{MH}}$, Mantel-Haenszel weighted odds ratio; $\mathrm{AR}$, absolute risk. ciated with development of insulitis and diabetes in NOD mice [5-8]. There have also been reports of nonHLA genes conferring susceptibility to IDDM in humans. However, apart from HLA, only polymorphisms in the insulin-IGF2 gene-region (INS) on chromosome 11, first described by Bell et al. [9], have repeatedly shown association to IDDM. Julier et al. [10] found that the IDDM associated INS polymorphism only conferred susceptibility in HLA-DR4-positive individuals. Other studies have found that polymorphisms in INS confer risk independently of HLA genotype [1113]. Most studies of this region have been performed in Caucasians [9-17]. Reports from Japanese oriental populations on associations between 5' variable number of tandem repeats (VNTR) polymorphisms in the INS region and IDDM have not been able to show significant association [18-22].

Trans-racial mapping studies have been a powerful tool in mapping which genes in the HLA region confer the primary susceptibility for IDDM $[1,23]$. We have studied the contribution of newly-identified markers in 
the insulin gene region on IDDM susceptibility in three ethnic groups; blacks, Caucasians and orientals. We typed 418 IDDM patients and 422 healthy control subjects for three polymorphisms; 1,127 Pst1, 1,404 Fnu4H and 1,428 Fok I that are situated 3' to the insulin gene [10]. An additional aim of this study was to evaluate the contribution of INS as a marker in IDDM prediction.

\section{Subjects and methods}

Subjects. IDDM patients and healthy control subjects from three countries and three ethnic groups were studied. The Caucasian dataset consisted of 244 randomly-selected unrelated Norwegian IDDM patients. All patients had an absolute insulin dependency (non-fasting serum C-peptide $<0.1 \mathrm{nmol} / \mathrm{l}$ ). The mean age of disease onset was 14 years. The distribution of HLA class II genes in 87 of these patients has been published previously [24]. A control group of 187 randomly-selected healthy subjects ( 130 blood donors and 57 members of the hospital staff) were included [25]. In addition 44 HLA-DR4-positive control subjects were selected from the Norwegian Bone Marrow Registry to allow comparison of INS genotype with HLA genotype. INS genotypes have been published previously for parts of this material [11].

The oriental dataset consisted of 114 randomly-selected Japanese IDDM patients and 141 randomly-selected healthy control subjects. All the patients were from the northern part of Kyushu Island and were all of Japanese ethnic background. The diagnosis of IDDM was made by the following criteria: non-fasting plasma C-peptide below $0.1 \mathrm{nmol} / \mathrm{l}$ and ketoacidosis at the onset or during the disease. The mean age of disease onset was 15.1 years (range $0-47$ ). The control subjects were randomly-selected members of medical staff and students living in the same area as the IDDM patients. HLA class II genotypes have been reported for this dataset previously [1].

The black dataset consisted of 60 unrelated IDDM patients from Tanzania. They had all been diagnosed under the age of 30 years at the Muhimbili Medical Centre in Dar-es-Salam where they had been receiving insulin therapy for at least 1 year before the collection of blood specimens for this study. Fifty non-diabetic control subjects were selected among members of the medical Centre.

Methods. The Japanese samples were genomically typed for HLA class II alleles in Japan [1], while the rest of the samples were typed in Oslo, using PCR-SSO as described elsewhere [24, 25]. To ascertain specific hybridisation, PCR-amplified DNA of 24 homozygous typing cells from the 10 th International Histocompatibility Workshop (IHWS) were always processed together with the samples tested.

The typing for INS polymorphisms of the whole material was carried out in Oslo using previously described methods [11]. Briefly, the typing was performed by enzymatic digestion of PCR amplified DNA. Two PCRs were performed, amplifying DNA sequences 3' to the insulin gene. PCR amplification was performed in a $25-\mu \mathrm{l}$ volume containing $100 \mathrm{ng}$ DNA, $0.5 \mathrm{mmol} /$ $\mathrm{MgCl}_{2}, 10 \mathrm{mmol} / 1$ Tris [Tris (hydroxymetyl) amino methane] buffer (pH 8.4) (Sigma Chemical Co, St. Louis, Mo., USA), $50 \mathrm{mmol} / \mathrm{l} \mathrm{KCl}$, "Tween 20 " $0.01 \%, 200 \mu \mathrm{mol} / 1$ of each $\mathrm{dNTP}$, $125 \mathrm{ng}$ of each primer and 0.5 units of Taq polymerase (Perkin Elmer, Norwalk, Conn., USA). Thirty-five cycles $\left(10 \mathrm{~s}\right.$ at $95^{\circ} \mathrm{C}$, $30 \mathrm{~s}$ at $55^{\circ} \mathrm{C}$ and $45 \mathrm{~s}$ at $72^{\circ} \mathrm{C}$ ) were performed in a Cetus 9600 . The sequences of the primers used are described elsewhere [11]. One of the PCR products was digested with Pst1. The other PCR product was digested with Fnu4 $\mathrm{H}$ and Fok1. The digested PCR products were electrophoresed on a gel consisting of $3 \% \mathrm{Nu}-$ Sieve GTG Agarose (FMC Bioproducts, Rockland, Me., USA) and $1.5 \%$ Agarose (Sigma Chemical $\mathrm{Co}$ ) and visualised by ethidium bromide staining. All samples were typed for the 1,127 Pst1 polymorphism. Since a strong linkage disequilibrium has been described between the 1,127 Pst1, 1,404 Fnu4H and 1,428 Fok1 polymorphisms, only 30 samples from each population, including patients and control subjects, were typed for the 1,404 Fnu4 $\mathrm{H}$ and the 1,428 Fok1 polymorphisms $[10,11,17,26]$.

\section{Statistical analysis}

Statistical analyses were performed by assessing relative risk by the method of Woolf. When a cell in the $2 \times 2$ table was zero Haldane correction was used [27]. Significance of difference was tested for by chi square or Fischer exact test when appropriate. A $p$ value $<0.05$ was considered significant. Absolute risks were calculated using Bayes theorem [28] and using a prevalence of IDDM in the Norwegian population of $0.6 \%$ (G. Joner, personal communication). Test for homogeneity across strata and Mantel Haenszel statistics was calculated using BMDP statistical software.

\section{Results}

INS haplotypes. We found no exceptions to the previously described linkage disequilibrium between the three polymorphic sites investigated in either of the populations studied. By means of complete correlation between genotypes at the three loci typed for in all populations we could identify two simulated haplotypes. The one previously reported to be associated to IDDM, here called INS +, does not have the polymorphic restriction sites designated 1,127 Pst1 and 1,428 Fok1 respectively, but does contain the polymorphic restriction site designated $1,404 \mathrm{Fnu} 4 \mathrm{H}$. The other haplotype (INS-) shows exactly the opposite pattern at these loci. Both Norwegian control subjects and IDDM patients had a significantly higher frequency of the rare INS ${ }^{-}$haplotype compared to the other populations studied $(p<0.005$; Table 1$)$. The different allele frequencies observed between Tanzanian blacks and Japanese Orientals did not reach statistical significance $(p=0.2$, when comparing control groups; Table 1$)$. The INS $^{-}$haplotype is very rare in our material and INS-1homozygous and INS $+1-$ heterozygous are pooled in the statistical analyses.

Norwegian Caucasians. The Norwegian dataset showed a clear association between the INS + I + genotype and IDDM giving a relative risk of $2.3, p<0.0001$ (Table 1). This dataset was large enough to allow stratification for some HLA-DR and -DQ genotypes. There were no significant differences in the different HLA genotype groups analysed (Table 2 ), nor were there significant signs of heterogeneity $(p=0.86)$. Thus, we found the INS $+1+$ genotype confered virtually the same relative 
Table 1. Frequencies of INS $+/+$ and $+/$ - or $-/$ in IDDM patients and control subjects at the 1,127 Pst 1 site

\begin{tabular}{|c|c|c|c|c|c|c|}
\hline \multirow[t]{2}{*}{ Population } & \multicolumn{2}{|c|}{ Control subjects } & \multicolumn{2}{|l|}{ Patients } & \multirow[t]{2}{*}{$R R^{a}$} & \multirow[t]{2}{*}{$p$} \\
\hline & $+\overline{1+}$ & $+1-$ or $-1-$ & $+1+$ & $+1-$ or -1 & & \\
\hline Norwegian & $120(64 \%)$ & $67(36 \%)$ & $197(81 \%)$ & $47(19 \%)$ & 2.3 & $<0.0001$ \\
\hline Japanese & $133(94 \%)$ & $8(6 \%)$ & $111(97 \%)$ & $3(3 \%)$ & 2.2 & $0.19^{\mathrm{b}}$ \\
\hline
\end{tabular}

a Comparing the INS $+1+$ genotype among patients and con-

ing no significant heterogeneity across the different populations trols.

${ }^{\mathrm{b}}$ One-sided $p$-values.

Test for homogeneity across populations was performed showstudied. The Mantel-Haenszel statistics from combining the two times two tables were $O R_{\mathrm{MH}}=2.41 ; 95 \%$ C.I. $(1.58-3.68)$, $p<0.0001$

Table 2. Frequencies of INS $+/+$ and $+/$ - or $-1-$ at the 1,127 Pst1 site in Norwegian IDDM patients and control subjects ${ }^{a}$ carrying the same HLA DR - DQ genotype

\begin{tabular}{|c|c|c|c|c|c|c|}
\hline \multirow[b]{2}{*}{$H L A$} & \multicolumn{2}{|c|}{ Control subjects } & \multicolumn{2}{|l|}{ Patients } & \multirow[t]{2}{*}{$R R$} & \multirow[t]{2}{*}{$p^{b}$} \\
\hline & $+1+$ & $+1-$ or $-1-$ & $+1+$ & $+1-$ or $-1-$ & & \\
\hline DR3-DQB1*0201/DR4-DQB1*0302 & $28(64 \%)$ & $16(36 \%)$ & $69(81 \%)$ & $16(19 \%)$ & 2.5 & 0.048 \\
\hline $\mathrm{Y} / \mathrm{Y}^{\mathrm{d}}$ & $94(64 \%)$ & $52(36 \%)$ & $37(77 \%)$ & $11(23 \%)$ & 1.9 & 0.071 \\
\hline
\end{tabular}

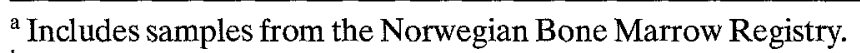

thus there was no significant heterogeneity across the different

${ }^{b}$ One-sided $p$-values.

${ }^{\mathfrak{c}} \mathrm{X}=$ any haplotype other than DR3-DQB1*0201.

${ }^{\mathrm{d}} \mathrm{Y}=$ any haplotype other than DR4-DQB1*0302.

Test for homogeneity gave a chi-square $=0.31(2 d f) ; p=0.86$, HLA class II strata. Mantel-Haenszel statistics when combining the $2 \times 2$ tables stratified for HLA: $O R_{\mathrm{MH}}: 2.18$; $95 \%$ C.I.: (1.36$3.55), p=0.002$

Table 3. Frequencies and AR for IDDM development for Norwegian individuals carrying particular HLA class II and INS genotypes/haplotypes

\begin{tabular}{|c|c|c|c|c|}
\hline \multirow[b]{2}{*}{ Genotype } & \multirow{2}{*}{$\begin{array}{l}\text { Control subjects } \\
n=187\end{array}$} & \multicolumn{3}{|l|}{ Patients } \\
\hline & & $n=201^{\text {a }}$ & $\operatorname{AR}(\%)$ & $95 \%$ C.I. $(\%)$ \\
\hline$\overline{\mathrm{INS}}+1+(n=244)^{\mathrm{a}}$ & $120(64 \%)$ & $197(81 \%)$ & 0.8 & $(0.7-0.9)$ \\
\hline DR3-DQB1*0201/ DR4-DQB1*0302 & $6(3 \%)$ & $85(42 \%)$ & 7.4 & $(3.4-15)$ \\
\hline DR3-DQB1*0201/ DR4-DQB1*0302 and INS + $1+$ & $5(3 \%)$ & $69(34 \%)$ & 7.2 & $(3.1-16)$ \\
\hline DR4-DQB1*0302+ ${ }^{b}$. & $41(22 \%)$ & $153(76 \%)$ & 2.1 & $(1.6-2.7)$ \\
\hline DR4-DQB1*0302 + and INS + / + & $26(14 \%)$ & $125(62 \%)$ & 2.6 & $(2.1-3.1)$ \\
\hline DR4-DQB1*0302_- ${ }^{c}$ & $146(78 \%)$ & $48(24 \%)$ & 0.2 & $(0.1-0.2)$ \\
\hline DR4-DQB1*0302-and INS + /+ & $94(50 \%)$ & $37(18 \%)$ & 0.2 & $(0.2-0.3)$ \\
\hline
\end{tabular}

a Of our 244 IDDM patients only 201 were typed for HLADQB1, while all 244 were typed for INS. Therefore $n$ in the calculations of AR is 201 except for the AR of being INS + I+ (without HLA stratification) where $n$ is 244 .

${ }^{b}$ At least one HLA class II haplotype is DR4-DQB1*0302.

${ }^{\mathrm{c}}$ No HLA class II haplotype is DR4-DQB $1 * 0302$.

risk regardless of HLA class II genotypes. Although the frequency of INS + / + was slightly smaller in the nonDR4 group, the allele frequencies did not vary between the DR4-positive and the DR4-negative IDDM patients ( $89 \%$ INS + alleles in both groups).

Tanzanian blacks. In the Tanzanians we also observed a tendency for an association between IDDM and the INS $+1+$ genotype conferring a relative risk of 4.0 , which, however, was not statistically significant $(p=0.085$; Table 1$)$. Only two patients carried the rare INS ${ }^{-}$allele.
The strata in the table are partly overlapping. AR is calculated based on an unconditioned probability (i.e. the probability of a person without known HLA class II genes or INS genotypes) of developing IDDM during a lifetime in Norway of $0.6 \%(0.006)$ (G. Joner personal communication)

Japanese orientals. RR for INS $+1+$ in Japanese was 2.2, approximately the same as in Norwegians. It did not reach statistical significance in Japanese in whom the frequency of the INS + I + genotype was very high (Table 1).

Absolute risks. To investigate the relative contribution of the INS gene region to IDDM development we have calculated the absolute risk (i.e. life-time risk) for IDDM in Norway. In Table 3 the absolute risk of IDDM for those being INS + / + is given. For comparison the absolute risks of known susceptibility HLA 
class II genotypes are also given $[1,24,25]$. As is apparent from Table 3 , there is not a strong contribution of the IDDM associated INS $+1+$ polymorphism to the absolute risk, compared to that associated with given HLA-DQ genes.

\section{Discussion}

The INS $+1+$ genotype confers susceptibility to IDDM in Norwegians while no significant association to IDDM is observed among Tanzanians and Japanese although the RR was increased in these populations also. The data suggest that INS confers susceptibility in an HLA-independent manner.

The Norwegian dataset confirms previous studies that have shown an increased frequency of the INS $+1+$ genotype in IDDM patients of Caucasoid origin [9-17]. The same association seems to be present among Tanzanian blacks, where the RR for INS $+/+$ is somewhat higher than in the Norwegian population, but the total numbers of patients and control subjects are much smaller and do not show statistically significant $p$ value. A previous study in American blacks failed to show any significant association between INS genotypes and IDDM [29]. The sample size in this study was, however, small $(n=27)$.

The Japanese population has a higher frequency of the INS $+1+$ genotype both among control subjects and IDDM patients than the other populations studied here. The relative risk is, however, comparable to that of the Norwegian dataset as well as that of other studies in Caucasians. The difference in frequency between patients and control subjects is, however, not significant in this population. This could reflect disease heterogeneity. The very high frequency of INS + $1+$ in Japanese is in agreement with studies applying the $5^{\prime} \mathrm{VNTR}$ polymorphism to assess the INS genotype [18-22]. None of these previous studies have shown any contribution of the INS region to IDDM susceptibility among Japanese subjects. Although there is no significant association between INS polymorphisms and IDDM among Japanese either in this or in previous studies, it cannot be ruled out that the INS region contributes to IDDM susceptibility among Japanese subjects. Firstly, the frequency of INS + $1+$ is very high among Japanese control subjects making a very large sample size necessary to detect an association. Secondly, the biologically important polymorphism in the INS region has to be identified and association studies performed before one can conclude that there is lack of association. Lucassen et al. [17] have most recently identified a cluster of polymorphisms, in a $4.1 \mathrm{~kb}$ region encompassing the insulin gene, which among Caucasians are in strong linkage disequilibrium making it difficult to pin-point the biologically important one. Several of these polymorphisms have not been studied among Japanese. The high frequency of INS $+/+$ in Japanese where the incidence of IDDM is low, may suggest that this polymorphism contributes little to susceptibility to the disease. In addition previous studies have shown that IDDM in Japanese subjects is associated with different HLA-DQ genes than in Caucasians [30,31].

Regarding HLA INS associations we find no support for the previous report of INS + / + conferring susceptibility only in HLA-DR4-positive individuals. There are no differences in allele frequencies of INS + in DR4positive and DR4-negative patients $(89 \%$ in both groups) and there is no significant heterogeneity. Thus, the slightly smaller RR obtained for DR4-negative patients in this study is probably due to chance and the lack of significant $p$ value for this group may be due to insufficient sample size. The DR4-DQB $1 * 0302$ haplotype is found in $76 \%$ of Norwegian IDDM patients, and no DR4-DQB1*0302 negative genotypes confer significant risk for IDDM among Norwegians [24]. The INS genotypes from some of the Norwegian material have been reported previously in a study that also included British patients, control subjects and multiplex families [11]. In the present study the material is, however, enlarged and HLA-DQ genotypes are included besides the HLA-DR genotypes reported previously. Our data are in agreement with other reports showing no INS HLA interactions [11-13] and thus are in conflict with the report by Julier et al. [10]. We cannot, however, completely rule out the possibility that the risk conferred by INS is slightly higher among DR4-positive individuals as suggested by Lucassen et al. [17].

The finding that INS confers susceptibility to IDDM independently of HLA is of great interest both theoretically and from a clinical point of view. A marker that confers susceptibility independently of HLA may be of greater value in identifying persons at high risk of developing IDDM. When we add the risk conferred by HLA and INS, the increase in absolute risk for IDDM is, however, small. This indicates that with the current markers used to assess INS genotypes, INS will not be very helpful in screening for IDDM risk.

In conclusion our data suggest that INS confers susceptibility to IDDM development in Caucasoids and that this effect is independent of HLA genotype. A similar, though not significant, tendency is observed among Tanzanian blacks. We find, however, that the INS polymorphism does not add greatly to the risk associated with given HLA polymorphisms.

Acknowledgements. This work was supported by The Research Council of Norway, Division NAVF and The Norwegian Diabetes Association. The visit to Tanzania to collect blood samples was supported by a grant from the Finnish Academy. The assistance of the Muhimbili Medical Centre in the field work in Tanzania is greatly appreciated. 


\section{References}

1. Rønningen KS, Spurkland A, Tait BD et al. (1993) HLA class II associations in insulin-dependent diabetes mellitus among blacks, Caucasoids and Japanese. In: Tsuji K, Aizawa M, Sasazuki T (eds) HLA 1991. Oxford University Press, Oxford, pp 713-722

2. Barnett AH, Eff C, Leslie RDG, Pyke DA (1981) Diabetes in identical twins. Diabetologia 20: 87-93

3. Kaprio J, Tuomilehto J, Koskenvuo M et al. (1992) Concordance for type 1 (insulin-dependent) and type 2 (non-insulindependent) diabetes mellitus in a population-based cohort of twins in Finland. Diabetologia 35: 1060-1067

4. Thomson G, Robinson WP, Kuhner MK et al. (1988) Genetic heterogeneity, modes of inheritance, and risk estimates for a joint study of Caucasians with insulin-dependent diabetes mellitus. Am J Hum Genet 43: 799-816

5. Ghosh S, Palmer SM, Rodrigues NR et al. (1993) Polygenic control of autoimmune diabetes in nonobese diabetic mice. Nature Genetics 4: 404-409

6. Todd JA, Aitman TJ, Cornall RJ et al. (1991) Genetic analysis of autoimmune type 1 diabetes mellitus in mice. Nature 351: 542-547

7. Wicker LS, Appel MC, Dotta F et al. (1992) Autoimmune syndromes in major histocompatibility complex (MHC) congenic strains of nonobese diabetic (NOD) mice. The NOD MHC is dominant for insulitis and cyclophosphamideinduced diabetes. J Exp Med 176: 67-77

8. Cornall RJ, Prins J-B, Todd JA et al. (1991) Type 1 diabetes in mice is linked to the interleukin-1 receptor and Lsh/Ity/Bcg genes on chromosome 1. Nature 353: 262-265

9. Bell GI, Horita S, Karam JH (1984) A polymorphic locus near the human insulin gene is associated with insulin-dependent diabetes mellitus. Diabetes 33: 176-183

10. Julier C, Hyer RN, Davies J et al. (1991) Insulin - IGF2 region on chromosome $11 \mathrm{p}$ encodes a gene implicated in HLA-DR-4 dependent diabetes susceptibility. Nature 54: 155-159

11. Bain SC, Prins J-B, Hearne CM et al. (1992) Insulin gene region-encoded susceptibility to type 1 diabetes is not restricted to HLA-DR4-positive individuals. Nature Genetics 2:212-215

12. Raffel LJ, Vadheim CE, Klein R et al. (1991) HLA-DR and the 5 ' insulin gene polymorphism in insulin-dependent diabetes mellitus. Metabolism 40: 1244-1248

13. Van der Auwera B, Heimberg H, Schrevens AF, Van Wayenberge C, Flament J, Schuit FC (1993) 5' insulin gene polymorphism confers risk to IDDM independently of HLA class II susceptibility. Diabetes 42: 851-854

14. Hitman GA, Tarn AC, Winter RM et al. (1985) Type 1 (insulin-dependent) diabetes and a highly variable locus close to the insulin gene on chromosome 11. Diabetologia 28:218222

15. Raffel LJ, Hitman GA, Toyoda H, Karam JH, Bell GI, Rotter JI (1992) The aggregation of the 5' insulin gene polymorphism in insulin dependent (type 1) diabetes mellitus. J Med Genet 29: 447-450

16. Ferns GAA, Hitman GA, Trembath R et al. (1986) DNA polymorphic haplotypes on the short arm of chromosome 11 and the inheritance of type I diabetes mellitus. J Med Genet 23: $210-216$
17. Lucassen AM, Julier C, Beressi JP et al. (1993) Susceptibility to insulin dependent diabetes mellitus maps to a $4.1 \mathrm{~kb}$ segment of DNA spanning the insulin gene and associated VNTR. Nature Genetics 4: 305-310

18. Awata T, Shibasaki Y, Hirai H, Okabe T, Kanazawa Y, TakakuF (1985) Restriction fragment length polymorphism of the insulin gene region in Japanese diabetic and non-diabetic subjects. Diabetologia 28: 911-913

19. Nomura M, Iwama N, Mukai M et al. (1986) High frequency of class 3 allele in the human insulin gene in Japanese type 2 (non-insulin-dependent) diabetic patients with a family history of diabetes. Diabetologia 29: $402-404$

20. Takeda J, Seino Y, Fukumoto H et al. (1986) The polymorphism linked to the human insulin gene: its lack of association with either IDDM or NIDDM in Japanese. Acta Endocrinol 113: 268-271

21. Aoyama N, Nakamura T, Doi K, Baba S, Takahashi R, Sugiyama $T$ (1986) Low frequency of 5'-flanking insertion of human insulin gene in Japanese non-insulin dependent diabetic subjects. Diabetes Care 9: 365-369

22. Matsumoto T, Awata T, Iwamoto Y, Kuzuya T, Saito T (1993) Lack of association of the insulin gene locus with type 1 diabetes in Japanese. Diabetes 42 [Suppl 1]: 110 A (Abstract)

23. Jenkins D, Mijovic C, Fletcher J, Jacobs KH, Bradwell AR, Barnett AH (1990) Identification of susceptibility loci for type 1 (insulin-dependent) diabetes by trans-racial gene mapping. Diabetologia 33: 387-395

24. Rønningen KS, Spurkland A, Iwe T, Vartdal F, Thorsby E (1991) Distribution of HLA-DRB1, -DQA1 and DQB1 alleles and DQA1-DQB1 genotypes among Norwegian patients with insulin-dependent diabetes mellitus. Tissue Antigens 37: 105-111

25. Rønningen KS, Spurkland A, Markussen G, Iwe T, Vartdal F, Thorsby E (1990) Distribution of HLA class II alleles among Norwegian Caucasians. Hum Immunol 29:275-281

26. Cox NJ, Bell GI, Xiang K (1988) Linkage disequilibrium in the human insulin/insulin-like growth factor II region of human chromosome II. Am J Hum Genet 43: 495-501

27. Tiwari JL, Terasaki $P$ (1985) The data and statistical analysis. In: Tiwari JL, Terasaki P HLA and disease associations. Springer Verlag New York Berlin Heidelberg Tokyo pp 1827

28. Neutra RR, Drolette ME (1978) Estimating exposure-specific disease rates from case-control studies using Bayes' theorem. Am J Epidemiol 108: 214-222

29. Elbein S, Rotwein P, Permutt A, Bell GI, Sanz N, Karam JH (1985) Lack of association of the polymorphic locus in the 5'flanking region of the human insulin gene and diabetes in American blacks. Diabetes 34: 433-439

30. Todd JA, Fukui Y, Kitagawa T, Sasazuki T (1990) The A3 allele of the HLA-DQA1 locus is associated with susceptibility to type 1 diabetes in Japanese. Proc Natl Acad Sci USA 87: 1094-1098

31. Yamagata K, Nakajima H, Hanafusa T et al. (1989) Aspartic acid at position 57 of HLA-DQ beta chain does not protect against type 1 (insulin-dependent) diabetes in Japanese subjects. Diabetologia 32: 762-764 